\title{
BMJ Open Trends in healthcare utilisation during COVID-19: a longitudinal study from the UK
}

\author{
Ana Howarth (D) , ${ }^{1,2}$ Morag Munro, ${ }^{1}$ Alf Theodorou, ${ }^{1,3}$ Peter R Mills (i) ${ }^{1,4}$
}

To cite: Howarth A, Munro M, Theodorou A, et al. Trends in healthcare utilisation during COVID-19: a longitudinal study from the UK. BMJ Open 2021;11:e048151. doi:10.1136/ bmjopen-2020-048151

- Prepublication history and additional online supplemental material for this paper are available online. To view these files, please visit the journal online (http://dx.doi.org/10. 1136/bmjopen-2020-048151).

Received 18 December 2020 Accepted 12 July 2021

Check for updates

(c) Author(s) (or their employer(s)) 2021. Re-use permitted under CC BY-NC. No commercial re-use. See rights and permissions. Published by BMJ.

${ }^{1}$ Cigna Europe, Greenock, UK ${ }^{2}$ Population Health Research Institute, St George's University of London, London, UK

${ }^{3}$ NewCourse, West Down Farm, Corton Denham, Sherborne, UK ${ }^{4}$ Department of Respiratory Medicine, Whittington Hospital, London, UK

Correspondence to

Dr Ana Howarth;

ana.howarth@cigna.com

\section{ABSTRACT}

Objective The first wave of the COVID-19 pandemic had a major impact on healthcare utilisation. The aim of this retrospective review was to quantify how utilisation of non-COVID care changed during this time so as to gain insight and inform planning of future services during potential second and subsequent waves.

Methods and analysis A longitudinal design was used to analyse anonymous private UK health insurer datasets covering the period of January 2018 to August 2020.

Taken as a measure of healthcare utilisation in the UK, incidence rates of claims broken down by service area and condition were calculated alongside overall monthly totals and costs. Pre-COVID-19 years were compared with the current year.

Results Healthcare utilisation during the first wave of COVID-19 decreased by as much as $70 \%$ immediately after lockdown measures were implemented. After 2 months, the trend reversed and claims steadily began to increase, but did not reach rates seen from previous years by the end of August 2020. Assessment by service and diagnostic category showed that most areas, especially those highly reliant on in-person treatment, reflected the same pattern (ie, rapid drop followed by a steady recovery). The provision of mental health services differed from this observed trend, where utilisation increased by $20 \%$ during the first wave of COVID-19, in comparison to pre-COVID-19 years. The utilisation of maternity services and the treatment of existing cancers also stayed stable, or increased slightly, during this time.

Conclusions Healthcare utilisation in a UK-based privately insured population decreased dramatically during the first wave of the COVID-19 pandemic, being over $70 \%$ lower at its height. However, mental health services remained resilient during this time, possibly due to greater virtualisation of diagnostics and care.

\section{INTRODUCTION}

In the aftermath of the first wave of the novel COVID-19, it is clear the impact of the global pandemic on healthcare systems has been acute. ${ }^{1}$ Most systems, regardless of location, have had to take immediate action ranging from rapid transitions to virtual care $^{2}$ to complete shutdowns. Fear of infection and reduced availability of healthcare services has led to reduced non-COVID healthcare utilisation worldwide. In Italy

\section{Strengths and limitations of this study}

- This longitudinal study evaluated healthcare utilisation within a private healthcare sample over 3 years enabling insight into health seeking behaviours during the first COVID-19 wave.

- Real-world monthly claims data for both service type and diagnostic category was assessed enabling comparative analysis.

- The data were limited to a population that were privately insured within a country where the majority use the government funded National Health Service.

- Although costs were analysed it was not possible to confirm whether other variables such as medical inflation or contracted rates might have influenced the unit cost of care or frequency of claims.

and Germany, ${ }^{3}{ }^{4}$ paediatric emergency room (ER) visits dropped by as much as $64 \%-88 \%$ while heart attack treatment rates in the USA decreased by $38 \%$ in some major hospitals. ${ }^{5}$

In the UK, the first identified cases of COVID-19 were reported at the end of January 2020, but the first person-to-person transmission was only confirmed in late February. ${ }^{6}$ On 11 March, WHO declared the spread of COVID-19 a pandemic and measures were taken nationally to slow the spread and protect healthcare systems. A UK national lockdown started on March 23rd and the public were informed to only to leave their homes for specific reasons such as food shopping, travel to work, once daily exercise and urgent medical needs. ${ }^{6}$ Further restrictions were imposed by mid-April. ${ }^{6}$

In addition to limiting population movement, physical distancing outside of the home was also advised and this perhaps triggered the beginning of the changes in healthcare utilisation by individuals. When considering visiting a hospital or clinic, members of the public were now tasked with weighing their risk of travelling, as well as visiting a setting which was a potential hotspot for infection. From the provider perspective, there was a scramble to triage the most urgent, but also 
the least at-risk patients, for in-person consultation. The challenge of providing healthcare during a pandemic for those with compromised immune systems ${ }^{7}$ has been a global issue. The short-term impact of COVID-19 has directly affected many individuals who have been infected, but also the wider population looking to access healthcare during this time. ${ }^{9}$

In the UK, approximately $10.5 \%$ of consumers have private medical insurance. ${ }^{10}$ There is little debate in relation to how severely most healthcare systems have been disrupted but the areas and services that have been able to adapt most effectively, often with the use of virtual care, may provide potential solutions for areas still lagging behind. This is especially critical at the moment as the UK has already experienced a second wave of COVID-19 infections where lockdown measures have been reimplemented ${ }^{11}$ and there are concerns about preparing for a third wave. In this study we sought to review trends in claims and costs for patient care collected over the past year up to the end of the first wave. The aim was to explore changes in how people were utilising care in comparison to previous years so as to assess overall stability. In the wake of the second wave of COVID-19, understanding where resources might be best directed could lead to an improved 'non-COVID' healthcare response.

\section{METHODS}

\section{Study design and data sources}

A longitudinal design was used to analyse frequency of healthcare service claims in the UK. This was not longitudinal in the sense that the same individuals were followed over time, rather it was the fully insured served population from one UK private health insurer. A prepared dataset was obtained from this insurance provider operating in the UK. The health insurance provider is only one of two providers that offer only employer sponsored cover with no direct to consumer products. The businesses that make up the clientele predominately consist of corporate or white-collar employee organisations across the UK. As it was not raw data and had been prepared in advance, we did not have to contend with missing data. Data were extracted in the form of monthly total number of claims, monthly total claimants, monthly total enrolled membership and provider billed costs for the period of January 2018 through to the end of August 2020. These data were then disaggregated into monthly totals by service area (eg, physiotherapy or specialist consultation) and condition (eg, musculoskeletal or mental disorders). For the frequency counts of monthly claims, it must be clarified that these do not represent medical encounters but instead a claim in a relevant pre-determined category according to the billing system of the insurance provider. As an example, someone requiring surgery may have claims in at least two categories according to service (eg, theatre charges and surgeon fees) for only one medical encounter.
The data from 2018 and 2019 from the same relative time period were averaged and considered to represent a typical 'pre-COVID-19' year. The data from 2020 were classified as the 'COVID-19' year.

\section{Patient and public involvement}

Patients were not actively recruited for this study as it was secondary use of an existing dataset and it contained no identifying or personal information at any point. As it was analysed and processed anonymously, clients and the public were not directly involved in this study.

\section{Statistical analysis}

As the ratios for each month varied based on fluctuating membership, the monthly frequency of claims was calculated as the frequency of claims per 1000 enrolled members. This frequency was calculated by $1000 \times$ [monthly number of claims total $\div$ monthly membership] for monthly totals. The frequency for claims by service and condition categories was also calculated in the same way. Changes in frequencies between the 'pre-COVID-19' year (January through August in 2018 and 2019 averaged) and the 'COVID-19' year (January through August 2020) were calculated as a percentage based on the per 1000 incident rates. The calculation was [incident rate difference $\div$ first incident rate $] \times 100$. Finally, percentage of claimants and corresponding costs by month of enrolled members from 2018 to 2019 to 2020 were calculated based on monthly totals of enrolled. Inferential statistical tests were not used in our study because it was a descriptive analysis using longitudinal data from the whole population rather than a sample.

\section{RESULTS}

The mean age of the population was $42.1( \pm 11.5$ years $)$ ranging from 20 to 65 years with an average of $52.4 \%$ being males. While not being able to confirm exact membership enrolment or divulge employer details, as this is industry sensitive information, it is possible to report that the minimum average monthly membership was $>260000$ with a maximum of just under 300000 . Based on frequency of claims per 1000 enrolled members, monthly totals for the pre-COVID-19 year and the COVID-19 year can be seen in table 1. Online supplemental material including a breakdown by service (online supplemental table S1) and condition (online supplemental table S2) at a monthly level is available. The biggest shift in claims frequency was directly after lockdown in the UK which started in late March. By the end of April, the rate of claims had decreased by almost $70 \%$ in comparison to the pre-COVID-19 years. To offer context, January and February 2020, reported slight increases and while March had a reported decrease in claims, it was only by $13 \%$. The impact of COVID-19 was most prominent in April and continued through to August where the overall claims rate was $42 \%$ less (at a rate of 54.8 claims per 1000 
Table 1 Frequency of claims by month per 1000 enrolled members from $2018 / 2019^{*}$ to 2020

\begin{tabular}{llll}
\hline Month & $\begin{array}{l}\text { Pre-COVID-19 } \\
\text { year* }\end{array}$ & $\begin{array}{l}\text { COVID-19 } \\
\text { year }\end{array}$ & $\begin{array}{l}\text { Difference in } \\
\text { claims/1000 } \\
\text { enrolled, \% }\end{array}$ \\
\hline January & 194.0 & 215.7 & 11 \\
\hline February & 175.4 & 199.3 & 14 \\
\hline March & 189.3 & 165.1 & -13 \\
\hline April & 167.7 & 51.7 & -69 \\
\hline May & 180.3 & 50.2 & -72 \\
\hline June & 165.7 & 73.5 & -56 \\
\hline July & 158.8 & 100.5 & -37 \\
\hline August & 95.0 & 54.8 & -42 \\
\hline
\end{tabular}

*Average of 2018 and 2019.

enrolled members) than the previous year (which was 95.0 claims per 1000 enrolled members).

The biggest decreases of the year for claims can be seen in May when the most restrictions had been applied across the general population.

In table 2, monthly calculated percentage of claimants demonstrate the same trend. Claimant numbers as a percentage of the covered population were approximately the same across the pre-COVID-19 years and COVID-19 year, in January and February. This shifted in March 2020 and the percentage of claimants dropped for the first time (by 1\%) compared with the pre-COVID-19 years. This decrease continued until May where a maximum decrease of $5 \%$ was recorded. Costs (in GB pounds) per claimant varied on a monthly basis across both pre-COVID-19 and COVID-19 years, but were not outside of the normal month-to-month variation seen in the pre-COVID period.

\section{Frequency of claims by condition}

The total claims per 1000 enrolled members can be seen below in table 3 as broken down by 16 condition areas. The largest decrease in claims by condition was

Table 2 Percentage of population who were claimants and monthly costs per claimant for 2018/2019* and 2020

\begin{tabular}{|c|c|c|c|c|c|}
\hline \multirow[b]{2}{*}{ Month } & \multicolumn{2}{|c|}{ Pre-COVID-19 year* } & \multicolumn{2}{|c|}{ COVID-19 year } & \multirow[b]{2}{*}{$\begin{array}{l}\text { Change in } \\
\text { claimants } \\
\text { by } \%\end{array}$} \\
\hline & $\begin{array}{l}\text { Claimants } \\
\text { by } \%\end{array}$ & $\begin{array}{l}\text { Average } \\
\text { cost per } \\
\text { claimant }\end{array}$ & $\begin{array}{l}\text { Claimants } \\
\text { by } \%\end{array}$ & $\begin{array}{l}\text { Cost } \\
\text { in } £\end{array}$ & \\
\hline January & 6.2 & $£ 867$ & 6.4 & $£ 851$ & 0.2 \\
\hline February & 6.1 & $£ 793$ & 6.3 & $£ 798$ & 0.3 \\
\hline March & 6.4 & $£ 815$ & 5.4 & $£ 829$ & -1.0 \\
\hline April & 6.1 & $£ 753$ & 2.0 & $£ 701$ & -4.1 \\
\hline May & 6.4 & $£ 789$ & 1.9 & $£ 818$ & -4.5 \\
\hline June & 6.2 & $£ 782$ & 2.7 & $£ 908$ & -3.5 \\
\hline July & 6.2 & $£ 815$ & 3.6 & $£ 906$ & -2.6 \\
\hline August & 5.8 & $£ 797$ & 3.4 & $£ 798$ & -2.4 \\
\hline
\end{tabular}

*Average of 2018 and 2019.
Table 3 Frequency of claims by condition and change in percentage from $2018 / 2019^{*}$ to 2020

\begin{tabular}{|c|c|c|c|}
\hline Condition & $\begin{array}{l}\text { Pre-COVID-19 } \\
\text { year* }\end{array}$ & $\begin{array}{l}\text { COVID-19 } \\
\text { year }\end{array}$ & $\begin{array}{l}\text { Change } \\
\text { in \% }\end{array}$ \\
\hline Respiratory system disease & 26.5 & 13.0 & -50.8 \\
\hline Injury and poisoning & 89.4 & 48.1 & -46.2 \\
\hline Circulatory system disease & 36.3 & 20.0 & -44.9 \\
\hline Nervous system disease & 60.2 & 33.7 & -44.1 \\
\hline Digestive system disease & 74.2 & 42.3 & -42.9 \\
\hline $\begin{array}{l}\text { Musculoskeletal system } \\
\text { disease }\end{array}$ & 483.9 & 283.5 & -41.4 \\
\hline $\begin{array}{l}\text { Skin and subcutaneous } \\
\text { disease }\end{array}$ & 33.6 & 21.0 & -37.6 \\
\hline Genitourinary system disease & 96.6 & 62.4 & -35.5 \\
\hline $\begin{array}{l}\text { Infectious and parasitic } \\
\text { disease }\end{array}$ & 2.9 & 1.9 & -35.1 \\
\hline $\begin{array}{l}\text { Endocrine, nutritional, } \\
\text { metabolic disease }\end{array}$ & 10.4 & 7.3 & -29.7 \\
\hline $\begin{array}{l}\text { Symptoms, signs, ill-defined } \\
\text { conditions }\end{array}$ & 182.1 & 146.7 & -19.4 \\
\hline Neoplasms & 127.9 & 111.6 & -12.8 \\
\hline Blood diseases & 2.3 & 2.1 & -8.7 \\
\hline Others & 5.0 & 4.9 & -2.9 \\
\hline Pregnancy, childbirth & 4.6 & 4.8 & 4.3 \\
\hline Mental disorders & 90.0 & 107.6 & 19.6 \\
\hline
\end{tabular}

*Average for 2018 and 2019.

seen for respiratory system diseases. This condition area decreased overall by almost $51 \%$ compared with previous years. Closely following this rate of decrease were conditions which all had decreases of over $40 \%$ (but less than $50 \%)$. These five conditions were general injury and/or poisoning $(46 \%)$ and diseases of the circulatory $(45 \%)$, nervous $(44 \%)$, digestive $(43 \%)$ and musculoskeletal (41\%) systems. Other decreases over 20\% (but under $40 \%)$ included conditions ranging from skin disease $(38 \%)$ to endocrine, nutritional and metabolic conditions at $30 \%$. After this, moderate to small decreases were found for categories including a vague 'symptom, signs, ill-defined condition' group (19\%), neoplasm $(13 \%)$, blood diseases $(9 \%)$ and unknowns categorised as 'others' $(3 \%)$. In contrast to all other conditions, pregnancy/childbirth and mental disorders increased overall in claims frequency by approximately $4 \%$ and $20 \%$, respectively.

When assessing rankings in table 3 , it can be seen that overall, the top ranked conditions, stayed the same in the COVID-19 year compared with previous years. Both pre-COVID-19 and COVID-19 years had musculoskeletal disease, the general 'symptoms, signs, ill-defined' category and neoplasm conditions with the highest incident rates per 1000 enrolled members. The real changes were more subtle with mental disorders moving up a place from fifth to fourth highest number of claims and a moderately larger gap between the top four conditions compared with all others. In the COVID-19 year this gap 
Table 4 Frequency of claims by service and change in percentage from 2018/2019 to 2020

\begin{tabular}{lrrr}
\hline Service & $\begin{array}{l}\text { Pre-COVID-19 } \\
\text { year* }\end{array}$ & $\begin{array}{l}\text { CoVID-19 } \\
\text { year }\end{array}$ & $\begin{array}{l}\text { Change } \\
\text { in \% }\end{array}$ \\
\hline Theatre charges & 47.7 & 21.4 & -55.2 \\
\hline Physiotherapy & 282.5 & 147.4 & -47.8 \\
\hline Surgeons and anaesthetist fees & 107.7 & 57.3 & -46.8 \\
\hline Package pricing & 19.5 & 10.8 & -44.3 \\
\hline Accommodation/consumables & 61.6 & 35.1 & -42.9 \\
\hline Others & 33.3 & 19.7 & -40.8 \\
\hline Chiro/osteopathy & 50.6 & 30.4 & -39.9 \\
\hline Cash benefit & 23.0 & 15.0 & -34.7 \\
\hline Treatment room charges & 43.1 & 28.6 & -33.8 \\
\hline GP consultations & 2.2 & 1.5 & -33.7 \\
\hline Specialist consultations & 279.5 & 193.9 & -30.6 \\
\hline Specialist fees & 15.1 & 10.9 & -28.1 \\
\hline Diagnostic services & 250.7 & 208.9 & -16.7 \\
\hline Chemotherapy/radiotherapy & 19.0 & 21.6 & 13.6 \\
\hline Psychiatric & 90.6 & 108.4 & 19.6 \\
\hline
\end{tabular}

*Average of 2018 and 2019.

GP, general practitioner.

was larger with previous years having a difference of only seven claims/1000 enrolled members and the COVID-19 year having a difference of more than 45 claims/1000 enrolled members.

\section{Frequency of claims by service}

The total claims per 1000 enrolled members can be seen below in table 4 as broken down by service (see online supplemental file 2) for a brief description of service categories). The largest decrease in claims was in relation to theatre charges, which corresponds with restrictions to elective surgical procedures during this time. Closely following this was physiotherapy $(48 \%)$, surgeon/anaesthetist services $(47 \%)$, package pricing $(44 \%)$ and accommodation/consumables (43\%) categories, all of which are related to surgical intervention or in-person delivery of care.

The next group of decreases were relatively moderate, mostly ranging from $31 \%$ to $41 \%$. The services included in this group were highly varied in type of claims and included chiropractic/osteopathy services (40\%), cash benefits $(35 \%)$ and specialist consultations (30\%). Of the areas that decreased from previous years, only specialist services and diagnostic services were less than $30 \%$, with rates of $28 \%$ and $17 \%$, respectively. Finally, two service areas contrasted the other trends and increased in comparison to previous years for claims by service. Chemotherapy/radiotherapy increased by $13.6 \%$ overall and mental health services increased by $20 \%$ compared with previous years.

When assessing rankings in table 4, the overall top ranked services were physiotherapy, specialist consultations, diagnostic services and surgeon/anaesthetist services. These were all over 100 claims/1000 enrolled members with only one group (ie, surgeon/anaesthetist services) being under the 200 claims. Ranking for highest number of claims in the COVID-19 year were slightly different with four services over 100 claims /1000 enrolled but only one service (ie, diagnostic services) over 200 claims which closely follows the general trend of decreased claims. The notable group of psychiatric service that contrastingly increased during the COVID-19 year (by 20\%) also rose up in the ranks from the 5th to 4th highest claim number with 108 claims/1000 enrolled.

Like the condition rates, changes within the group rankings overall were subtle with gaps between rankings being wider in the COVID-19 year versus the pre-COVID-19 year. During the pre-COVID-19 years, the difference between rankings after the top 4 to 5 ranked services, was relatively gradual with no more than 25 claims difference between rankings and most commonly about 10 claims. During the COVID-19 year, this change with a strong divide between the top four ranked services, the lowest of which was 108 claims/1000 enrolled (ie, psychiatric service) and the next rank down which was almost half that amount with 57 claims/1000 enrolled.

\section{DISCUSSION}

The impact of COVID-19 has challenged healthcare systems worldwide. During the first wave of the pandemic the UK experienced the highest mortality rate in Europe, closely followed by Belgium, Italy and Spain. ${ }^{1}$ This study sought to explore the UK's response in healthcare utilisation as measured by frequency of claims submitted to a private health insurer. Our aim was to tease out potential trends that might shed light on how the first wave impacted healthcare provision so as to potentially support response planning during subsequent waves.

Claims submitted in 2020, from January through August, which captured the build-up and completion of the first COVID-19 wave, were compared with the average of two previous years for the same time period. Our findings show that the trends in healthcare utilisation in the UK private sector reflect that which has been reported globally. ${ }^{12-14}$ Our data show a sizeable drop in care utilisation for almost all services and diagnostic categories. The exception to this trend being for those with mental health and maternity needs, as well as those requiring chemotherapy and radiotherapy services.

During the first wave of the pandemic the UK's National Health Service (NHS) and the private health sector worked in collaboration to ensure individuals received care based on clinical need, rather than funding origin. With many NHS hospitals focused solely on managing patients with COVID-19 private sector providers treated many NHS patients based on the agreed clinical necessity criteria. This meant that regardless of whether a patient had private insurance or not, all patients were triaged to access care in the same way. Our data could therefore be considered to be a reasonable representation of the 
impact of the pandemic on the different aspects of nonCOVID care across the nation. This means the data for this study did not include any COVID-19-related care utilisation. Combined with public health measures (eg, lockdown and masking) that potentially reduced the influenza season, this may in some part explain why the respiratory conditions showed the largest drop in utilisation in this private healthcare analysis. Along the same lines, the category of injury (and poisoning) saw the second largest reduction, which may also have been influenced by lockdown measures severely limiting physical activities.

There has been much written in the scientific literature and popular press about how the pandemic, and the consequent reduction in care provision, has had a profound impact on the timeliness of diagnosing and treating may conditions, including cancer. ${ }^{15}$ Our findings suggest that there was an appreciable reduction in new claims for neoplasms $(12.8 \%)$, which is likely to reflect a delay in diagnosing individuals with cancer. However, we did see a relative increase in the number of claims for cancer treatment in the form of chemotherapy and radiotherapy, suggesting that those patients who already had a diagnosis at the time of lockdown were not impacted to the same degree.

Another area where substantial change in claims activity was seen is that of psychological and emotional health. Considerable concern has been raised in relation to mental health during the course of the pandemic, with the associated physical distancing and quarantining requirements exacerbating existing mental health issues and potentially contributing to new ones. ${ }^{16}$ A recently published study comparing mental health trends longitudinally for over 40000 participants found that by the end of April 2020, the quality of the mental health of adults in the UK had decreased in comparison to pre-COVID-19 years. ${ }^{17}$ Our research very much supported this across claims in both the conditions and services categories. Under the condition category of mental disorders and under the service category of psychiatry, rates of claims at the start of the year were found to be slightly higher than previous years, but unlike other years, the trend did not decrease. In contrast to almost all other claim areas by April both categories had increased compared with pre-COVID-19 years. This is perhaps the most poignant take away for future risk management within healthcare. While better treatment strategies for hospitalised COVID-19 patients are being developed and early vaccine results are promising, ${ }^{18} 19$ the deterioration of mental health appears to be widespread ${ }^{17}$ regardless of infection status. It is worth noting that remote delivery of psychological consultations and therapies was commonplace in the private healthcare sector, even before the pandemic, and it appears that this was rapidly 'ramped up' to meet the burgeoning demand during this period.

As many countries have now entered a second wave of COVID-19 infections and have reimplemented societal restrictions, it is clear that care for individuals with nonCOVID health issues will continue to be impacted. Virtual care delivery may help plug some of the diagnostic and treatment gaps that will inevitably occur until widespread vaccination can be delivered.

\section{Strengths and limitations}

A strength of this study is the longitudinal nature of the data that was collected, which allowed for a stronger comparative analysis. As well, the ability to look at this data as both service type and diagnostic category offered insight into what was driving any changes in trends and which areas were impacted most. In contrast, a weakness of this study is that it was limited to a population with private health insurance within the UK specifically, with our ability to generalise findings to the broader population unclear. While it is essential to have quantitative data addressing objective health behaviours (ie, submitted healthcare claims), ideally qualitative data in relation to what motivated people to change their health seeking behaviours would also have been advantageous. As it stands, the data was only able to offer a descriptive snapshot of this unique time period and without more granular information in relation to potential confounding variables, a more complex analysis was not possible.

\section{CONCLUSIONS}

Overall, our findings reflect the direct impact of COVID-19 on healthcare delivery systems across the UK, with a sudden decrease in utilisation being observed in April and May immediately following the implementation of lockdown measures. The steady recovery after this time up until August indicates a level of resilience for all types of service. As we enter the second wave of COVID-19 infections we have a real opportunity to strengthen the provision of non-COVID care across all service and diagnostic categories. The relative success of the provision of psychological healthcare services is a potential blueprint for others to use so that traditional face-to-face care is augmented, and potentially sometimes replaced, by virtual delivery methods.

Contributors AH and PRM conceived and designed the study. MM extracted and supported data preparation. AH, PRM and AT performed the data analysis and AH and PRM drafted the first version of the manuscript. All authors critically reviewed the manuscript and approved the final version.

Funding The authors have not declared a specific grant for this research from any funding agency in the public or not-for-profit sectors. This work was funding by Cigna Europe and Global Segments.

Competing interests All authors are either directly employed or contracted by Cigna Europe \& Global Segments.

Patient consent for publication Not required.

Provenance and peer review Not commissioned; externally peer reviewed.

Data availability statement No data are available. The data generated and analysed during the present study are only for private use and are not publicly available.

Supplemental material This content has been supplied by the author(s). It has not been vetted by BMJ Publishing Group Limited (BMJ) and may not have been peer-reviewed. Any opinions or recommendations discussed are solely those of the author(s) and are not endorsed by BMJ. BMJ disclaims all liability and responsibility arising from any reliance placed on the content. Where the content 
includes any translated material, BMJ does not warrant the accuracy and reliability of the translations (including but not limited to local regulations, clinical guidelines, terminology, drug names and drug dosages), and is not responsible for any error and/or omissions arising from translation and adaptation or otherwise.

Open access This is an open access article distributed in accordance with the Creative Commons Attribution Non Commercial (CC BY-NC 4.0) license, which permits others to distribute, remix, adapt, build upon this work non-commercially, and license their derivative works on different terms, provided the original work is properly cited, appropriate credit is given, any changes made indicated, and the use is non-commercial. See: http://creativecommons.org/licenses/by-nc/4.0/.

\section{ORCID iDs}

Ana Howarth http://orcid.org/0000-0002-3519-0989

Peter R Mills http://orcid.org/0000-0002-5892-2345

\section{REFERENCES}

1 Kontis V, Bennett JE, Rashid T, et al. Magnitude, demographics and dynamics of the effect of the first wave of the COVID-19 pandemic on all-cause mortality in 21 industrialized countries. Nat Med 2020;26:1919-28.

2 Mehrotra A, Ray K, Brockmeyer DM. Rapidly Converting to 'Virtual Practices': Outpatient Care in the Era of Covid-19. NEJM Catalyst 2020.

3 Lazzerini M, Barbi E, Apicella A, et al. Delayed access or provision of care in Italy resulting from fear of COVID-19. Lancet Child Adolesc Health 2020;4:e10-11.

4 Dopfer C, Wetzke M, Zychlinsky Scharff A, Happle C, et al. COVID-19 related reduction in pediatric emergency healthcare utilization - a concerning trend. BMC Pediatr 2020;20:427.

5 Garcia S, Albaghdadi MS, Meraj PM, et al. Reduction in STsegment elevation cardiac catheterization laboratory activations in the United States during COVID-19 pandemic. J Am Coll Cardiol 2020;75:2871-2.

6 Flynn Det al. COVID-19 pandemic in the United Kingdom. Heal Policy Technol 2020;9.

7 Alromaihi D, Alamuddin N, George S. Sustainable diabetes care services during COVID-19 pandemic. Diabetes Res Clin Pract 2020;166:108298.
8 De Guzman R, Malik M. Dual challenge of cancer and COVID-19: impact on health care and socioeconomic systems in Asia Pacific. JCO Glob Oncol 2020;6:906-12.

9 Deepthi R, Mendagudali R, Kundapur R. Primary health care and COVID-19 pandemic. Int J Heal Syst Implement Res 2020;4:20-9 https://ijhsir.ahsas-pgichd.org/index.php/ijhsir/article/view/84

10 Thorlby R. Health system overview: England, 2020. Available: https:// www.commonwealthfund.org/international-health-policy-center/ countries/england

11 Karlsson U, Fraenkel C. Covid-19 : risks to healthcare workers and their families Mistakes made in the first wave must not be repeated in the second. BMJ 2020;371:1-2.

12 Liang $\mathrm{Y}$, Chang $\mathrm{C}$, Chen $\mathrm{Y}$, et al. Symptoms, management and healthcare utilization of COPD patients during the COVID-19 epidemic in Beijing. Int $J$ Chron Obstruct Pulmon Dis 2020;15:2487-94.

13 Kumar R, Singh Bhadoria A. Covid-19: estimation of the severity and healthcare Utilization-A model based analysis. Int J Adv Sci Technol 2020;29:15164-71 http://sersc.org/journals/index.php/IJAST/article/ view/32456

14 World Health Organisation. COVID-19 significantly impacts health services for non communicable diseases, 2020. Available: https:// www.who.int/emergencies/diseases/novel-coronavirus-2019/advicefor-public?gclid=CjOKCQjwxdSHBhCdARIsAG6zhIXGm1wWSPLuNLGDfZPWXjQdjEImDpmwTKju3HNNAT6LIVmxO0czWAaAnM TEALw_wcB

15 Maringe C, Spicer J, Morris M, et al. The impact of the COVID-19 pandemic on cancer deaths due to delays in diagnosis in England UK: a national, population-based, modelling study. Lancet Oncol 2020;21:1023-34.

16 Giallonardo V, Sampogna G, Del Vecchio V, et al. The impact of quarantine and physical distancing following COVID-19 on mental health: study protocol of a multicentric Italian population trial. Front Psychiatry 2020;11:533.

17 Pierce $\mathrm{M}$, Hope $\mathrm{H}$, Ford $\mathrm{T}$, et al. Mental health before and during the COVID-19 pandemic: a longitudinal probability sample survey of the UK population. Lancet Psychiatry 2020;7:883-92.

18 Callaway E. What pfizer' S landmark COVID vaccine results mean for the pandemic. Nature 2020:1-8.

19 NIH (National Institutes of Health). Promising interim results from clinical trial of NIH-Moderna COVID-19 vaccine, 2020. Available: https://www.nih.gov/news-events/news-releases/promising-interimresults-clinical-trial-nih-moderna-covid-19-vaccine 